\title{
Demographic Characteristics of Non-directed Altruistic Kidney Donors in the United States
}

Faber DA ${ }^{3}$, Joshi $\mathbf{S}^{1,2}$ and Ciancio $\mathbf{G}^{3^{*}}$

${ }^{1}$ Department of Medicine, Jackson Memorial Hospital, Miami, Florida, USA

${ }^{2}$ Department of Medicine, University of Miami Miller School of Medicine, Miami, Florida, USA

${ }^{3}$ Department of Surgery, Division of Transplantation, University of Miami Miller School of Medicine, Miami, Florida, USA

\begin{abstract}
Among transplant centers in the US, the acceptance of kidneys from non-directed, altruistic donors is a relatively recent phenomenon, beginning in the late 1990's. Originally starting out as a handful each year, the number of nondirected donations has since increased to now represent over 3\% of the annual living donor pool of transplanted kidneys. The psychosocial and functional outcomes of non-directed donors have been extensively studied, yet the demographic characteristics of these donors have largely escaped analysis on a national-level. We examined national UNOS data from the past 27 years to understand the demographic characteristics of non-directed donors by gender, ethnicity, citizenship status, UNOS region, and ABO blood type. In this analysis, we found that: non-directed donors are an increasingly important source of kidneys; non-directed donors have tended to be male, white, and US citizens; several UNOS regions $(5,7$, and 9 in particular) are more prolific in performing non-directed donations than others; and non-directed donors are more likely to be of either $A B O$ type $O$ or $A$. Continued study of this population is needed to understand how these non-directed donor demographic characteristics may change over time.
\end{abstract}

Keywords: Live donor transplantation; Non-directed; Kidney transplantation; Altruistic; Demographics; Characteristics

\section{Introduction}

In the majority of cases, living kidney donors have some connection to a potential recipient on the waiting list, either as a direct genetic relative (sibling, parent, etc.) or an unrelated emotional one (spouse, friend, etc.). Though living donors (LDs) were once restricted to genetic relatives of the recipient, improvements in immunosuppressive therapy and developments of surgical procedures with low morbidity and mortality now allow living unrelated donors (LURDs) to make up a substantial portion of the living donor pool. In addition, the recent advent of paired exchanges and donation chains have allowed LURDs to donate, and their loved ones to receive a kidney, despite the fact that the donor kidney is not transplanted into his or her relative. These "directed" donations make up the vast majority of living donor cases.

Yet for many years, transplant centers received periodic "altruistic" requests to donate from members of the community who were entirely unrelated to any potential recipient, who wished to donate a kidney to the next, most appropriate person on the cadaver waiting list. These "non-directed" potential donors were at first categorically turned away, as transplant centers were concerned that anyone who wished to donate one of their organs to an unknown individual may harbor underlying psychiatric disease or these donors would request monetary payment from either the recipient or the hospital [1].

It was not until the late 1990s that US transplant centers took a second look at this potential donor pool. The first report of nondirected donation was published in 2000, with national practice guidelines coming shortly thereafter in 2002 [2,3]. Since these first steps, transplant centers around the country have been more willing to accept non-directed donors (NDDs), to the extent that they now make up roughly $3 \%$ of the annual living donor pool.

Extensive literature has been published with regard to NDDs, though this literature focuses mainly on ethical considerations, guidelines, and psychosocial workup, evaluation, and outcomes [4]. However, little has been published on the demographics of NDDs - their gender, ethnicity, citizenship status, etc. - especially in the United States (US). Work that has been done thus far focuses on the experiences of a single center, rather than the country at large [1,5-9]. To our knowledge, the last scholarly publication looking at national demographic data of NDDs in the US was published in 2003 [10].

Today, with nearly 1800 non-directed donations having been performed in the past 15 years in the US, it is important to know the characteristics of these individuals and the developing nationwide trends, not only so that we may understand them, but so that perhaps we may encourage other individuals to become NDDs themselves. In this paper, we will briefly examine the recent literature regarding the demographic makeup of NDDs both in the US and worldwide, as well as review the national statistics from the United Network for Organ Sharing (UNOS) to get a more complete sense for how their characteristics in the US have changed over the past 15 years.

\section{Data Review}

\section{Recent NDD literature}

The most recent publication looking at national demographic data of NDDs in the US was published in 2003. At the time, the data included a total of 73 NDDs performed between January 1, 1996 and July 1,2002 . The number was increasing each year, beginning with 5 NDDs performed in 1999, and rising to 27 in the full year of 2001; 24 NDDs had been performed the first six months of 2002 at the time the paper was accepted for publication [10].

*Corresponding author: Gaetano Ciancio, MD, MBA, Highland Professional Building, 1801 NW 9th Avenue, 5 th Floor, Miami, FL 33136, USA, Tel: 305-355511, Fax: 305-355-5217; E-mail: gciancio@med.miami.edu

Received: December 28, 2015; Accepted: April 01, 2016; Published: April 15, 2016

Citation: Faber DA, Joshi S, Ciancio G (2016) Demographic Characteristics of Non-directed Altruistic Kidney Donors in the United States. J Kidney 2: 121. doi:10.4172/2472-1220.1000121

Copyright: $\odot 2016$ Faber DA, et al. This is an open-access article distributed unde the terms of the Creative Commons Attribution License, which permits unrestricted use, distribution, and reproduction in any medium, provided the original author and source are credited. 
Citation: Faber DA, Joshi S, Ciancio G (2016) Demographic Characteristics of Non-directed Altruistic Kidney Donors in the United States. J Kidney 2: 121. doi: $10.4172 / 2472-1220.1000121$

Page 2 of 5

Since then, many of the recent papers looking at NDDs look only at the data of a single center. In the US, reports have been published from Utah (20 donors), Minnesota (22 donors), and Rhode Island (11 and 39 donors, respectively) [1,6-8]. From abroad, reports from individual centers in Sweden (3 donors), New Zealand (17 donors), and the Netherlands ( 8 donors) have been published $[5,9,11]$. However, the demographic characteristics collected in each of these reports differed widely; some collected only gender and age, while others tracked more detailed statistics such as college education and marriage status.

An evaluation of national-level data from the UK between was recently published in 2014, which compared the demographics and outcomes of 148 NDDs to those of 148 directed donors. Non-directed donation became legal in the UK in 2006, and as a result the number of non-directed donations that have been performed lags behind that of the US. This detailed analysis compared donors of both types across a number of demographic and psychosocial criteria, noting that NDDs are older than their directed donor counterparts, and that the number of non-directed donations performed in the UK is rising each year [4].

The largest evaluation of national-level US demographic data was included in a recent paper looking at subjective scores of "well-being" and how that predicted the rate of non-directed donation in all 50 US states. NDDs in between 1999 and 2010 were included in the analysis, which encompassed 955 non-directed donations. Evaluation of demographic data showed a population of NDDs that skewed slightly female, was centered around 40 years old, and was predominantly white [12].

\section{Comprehensive national UNOS data}

Statistics on non-directed donation in the US are maintained by UNOS, and are based on Organ Procurement and Transplantation Network (OPTN) data stretching back to 1988. Collected statistics that were used in this data analysis include donor gender, ethnicity, citizenship status, UNOS region of the country in which the procedure was performed, and $\mathrm{ABO}$ blood type (Table 1). As of December 26 , 2015, data from January 1, 1988 to September 30, 2015 was included in this analysis. In that time period, there were 132,165 living donor transplants performed, of which 1,767 were non-directed (1.3\%) [13].

Following the first reports of non-directed donations in 2000, the number of non-directed donations rose steadily from 2 in 1998 to an annual maximum of 210 performed in 2010 (Figure 1). In 2011, the number of non-directed donations dropped to 157 , though has been

\begin{tabular}{|c|c|c|c|}
\hline Demographic Variable & & $\mathbf{n}$ & Percentage of Donors \\
\hline \multicolumn{4}{|l|}{ Sex } \\
\hline & Male & 1045 & 59.14 \\
\hline & Female & 722 & 40.86 \\
\hline \multicolumn{4}{|l|}{ Ethnicity } \\
\hline & White & 1182 & 66.89 \\
\hline & Black & 287 & 16.24 \\
\hline & Hispanic & 151 & 8.55 \\
\hline & Asian & 107 & 6.06 \\
\hline & American Indian/Alaska Native & 17 & 0.96 \\
\hline & Pacific Islander & 12 & 0.68 \\
\hline & Multiracial & 11 & 0.62 \\
\hline \multicolumn{4}{|l|}{ Citizenship Status } \\
\hline & US Citizen & 1671 & 94.57 \\
\hline & Resident Alien & 54 & 3.06 \\
\hline & Non-resident Alien & 19 & 1.08 \\
\hline & Non-US Citizen/US Resident & 12 & 0.68 \\
\hline & $\begin{array}{c}\text { Non-US Citizen/Non-US Resident, to US } \\
\text { not for Tx }\end{array}$ & 3 & 0.17 \\
\hline & $\begin{array}{l}\text { Non-US Citizen/Non-US Resident, to US } \\
\text { for Tx }\end{array}$ & 8 & 0.45 \\
\hline \multicolumn{4}{|l|}{ UNOS Region } \\
\hline & Region 1 & 171 & 9.68 \\
\hline & Region 2 & 225 & 12.73 \\
\hline & Region 3 & 67 & 3.79 \\
\hline & Region 4 & 36 & 2.04 \\
\hline & Region 5 & 296 & 16.75 \\
\hline & Region 6 & 126 & 7.13 \\
\hline & Region 7 & 246 & 13.92 \\
\hline & Region 8 & 107 & 6.06 \\
\hline & Region 9 & 284 & 16.07 \\
\hline & Region 10 & 112 & 6.34 \\
\hline & Region 11 & 97 & 5.49 \\
\hline \multicolumn{4}{|l|}{ ABO Blood Type } \\
\hline & $\mathrm{O}$ & 679 & 38.43 \\
\hline & A & 710 & 40.18 \\
\hline & $\mathrm{B}$ & 275 & 15.56 \\
\hline & $A B$ & 103 & 5.83 \\
\hline
\end{tabular}

Table 1: Demographic chacteristics of nondirected donors in the US, 1 Jan 1999-30 Sept 2015. 
steadily rising to 183 in 2014, the most recent full year for which data are available. 138 non-directed transplants have been performed in 2015 up through September 30, which puts the US on track for 184 non-directed transplants this year if the same rate of donation holds true for October, November, and December. In each year since 1998, NDDs have tended to make up an increasing percentage of overall LDs. These two curves trend almost identically from 1998-2014, and in fact may be so similar in light of the fact that non-directed donation is a subtype of living donation, and subject to similar factors of influence.

NDDs have tended to be male (Figure 2). Of the overall total 1767 NDDs, 1045 have been male (59.14\%). Men have made up the majority of NDDs every year except for 1999 (when only 5 non-directed donations were performed) and 2000 (when there were 10 female and 10 male NDDs). This stands in contrast to prior reports, in which the majority of NDDs were female, though is in line with the overall group of LDs, which has skewed male every year since 1988.

As with other reports, NDDs in the US overall have tended to be white (Figure 3). The annual percentage of white NDDs has hovered around $70 \%$ of all NDDs, with Black, Hispanic, and Asian making up the next most common ethnicities of NDDs.

American Indian/Alaska Native, Pacific Islander, and Multiracial ethnicities are also tracked in UNOS data, each making up less than $1 \%$ in 2014. The percentage of black NDDs hit a high of $22.29 \%$ in 2011 , though has since fallen by half; the difference was almost entirely made up by a corresponding increase in white NDDs.

The overwhelming majority of NDDs are US citizens (Figure 4).

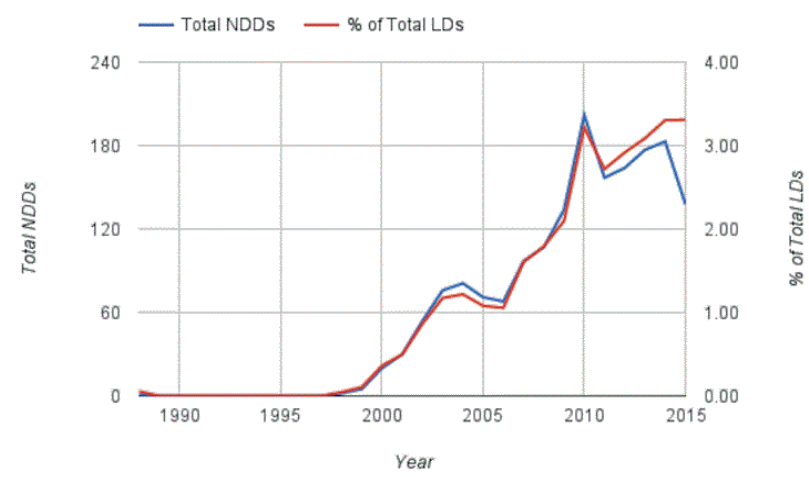

Figure 1: Total nondirected donors (NDDs) and percentage of total living donors (LDs) by year of donation, 1988-2015.

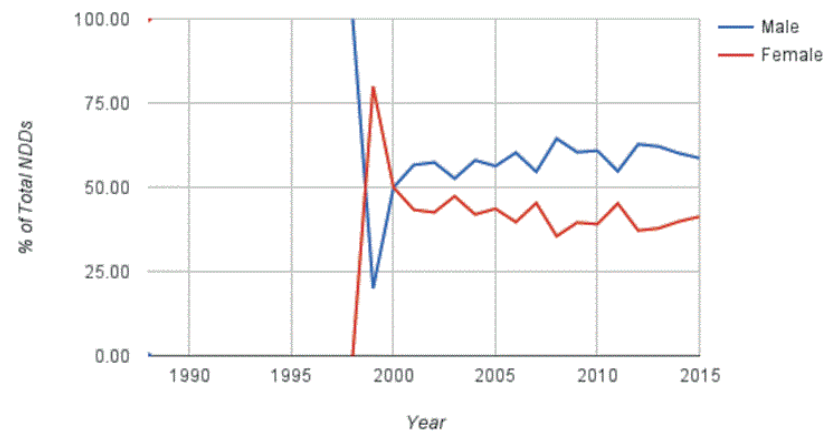

Figure 2: Percentage of nondirected donors (NDDs) by gender by year of donation, 1988-2015.

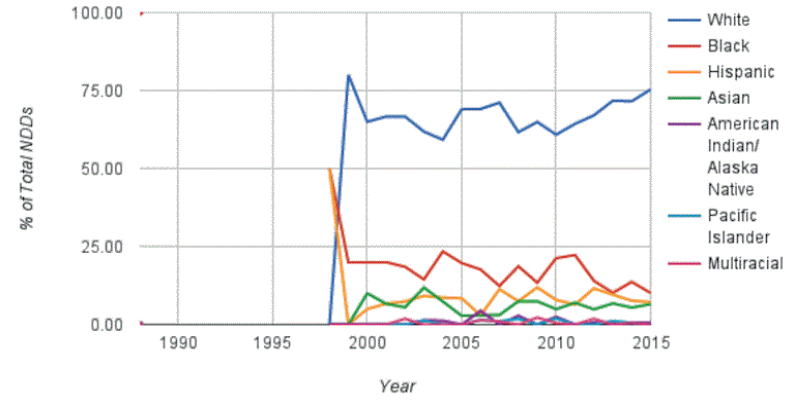

Figure 3: Percentage of nondirected donors (NDDs) by ethnicity by year of donation, 1988-2015.

Though UNOS tracks the immigration status of each NDD, US citizens have made up over $90 \%$ of all NDDs in every year since 1988. Resident aliens make up the second-most common citizenship of NDDs.

NDDs take place in each of the 11 UNOS regions across the US. To date, Region 5 (Arizona, California, Nevada, New Mexico, and Utah) has performed the most non-directed donations, 296 (16.75\% of all NDDs). Region 9 (New York and western Vermont), with 284 non-directed donations performed (16.07\% of all NDDs) and Region 7 (Illinois, Minnesota, North Dakota, South Dakota, and Wisconsin), with 246 non-directed donations performed (13.92\% of all NDDs), round out the top 3. Of note, Region 9 has performed only $7.81 \%$ of all LD surgeries since 1988, yet has done more than double that percentage (16.07\%) of non-directed donations (Figure 5). Since 2004, Region 9 has aggressively expanded its annual percentage of NDDs performed, reaching an annual peak of $23.26 \%$ in 2008, and has been below $20 \%$ of nationwide NDDs just once in the past 5 years. At the same time, Region 7 has lost a significant share of the NDDs; its annual NDD percentage sits at $11.48 \%$ in 2014, down from a high of $25.35 \%$ in 2005 .

Of all LDs performed, the most common annual ABO blood type is $\mathrm{O}$; NDDs, however, tend are most commonly either of $\mathrm{ABO}$ type $\mathrm{O}$ or A (Figure 6). Amongst NDDs, Type A has been the most common $\mathrm{ABO}$ type in 4 of the 6 years since 2010. ABO types $\mathrm{B}$ and $\mathrm{AB}$ were represented far less frequently, in proportions matching that of the larger general LD pool.

\section{Discussion}

To the best of our knowledge, this is the largest analysis of NDDs in the US to date. Previous reports have mainly focused on the experiences of a single center; larger, national-level analyses have been sparingly performed, with a dedicated analysis most recently in 2003.

Since first being used as viable kidney donors in the late 1990's, NDDs have become increasingly used. Our analysis shows that, as a percentage of total LDs, NDDs have risen to be an annual maximum of $3.31 \%$ in 2014; At the same time, the absolute number of NDDs hit a high of 210 in 2010, but has since risen each year since falling to 157 in 2011. Now that more transplant centers are willing to consider NDDs as viable organ donors, the rising number of NDDs per year is no surprise. The increase in the annual percentage of NDDs indicates that the rate of growth of NDDs is larger than that of the larger LD pool, which may be due to increased awareness due to media coverage (NDDs are often highly publicized by transplant centers and news media in the local area), an increased willingness to donate, or increased outreach. Though the peak of NDD seems to have been in 2010, the total number of LDs dropped off severely the following year as well, from 6278 in 2010 to 


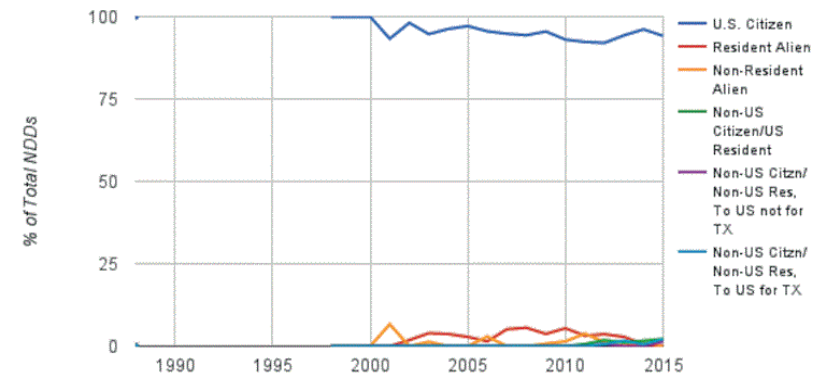

Figure 4: Percentage of nondirected donors (NDDs) by citizenship status by year of donation, 1988-2015.

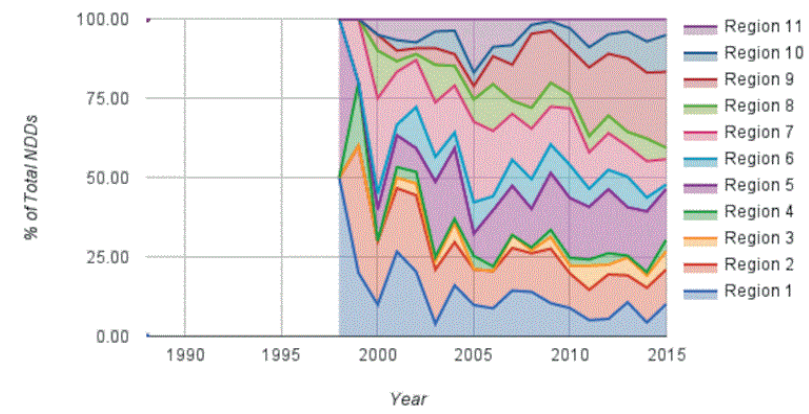

Figure 5: Percentage of nondirected donors (NDDs) by UNOS Region by year of donation, 1988-2015.

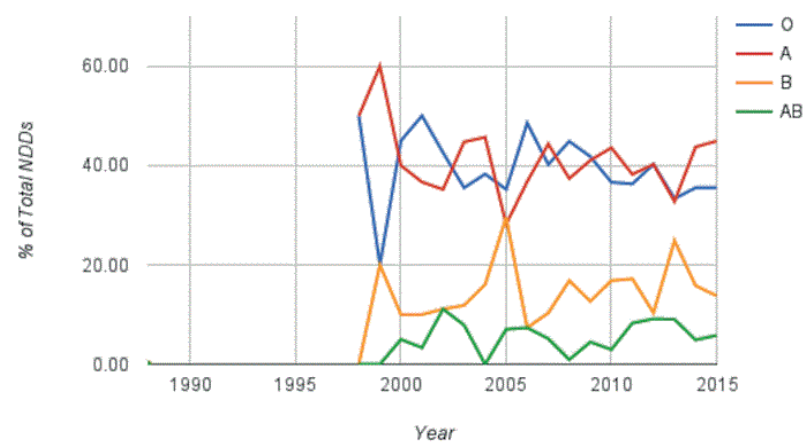

Figure 6: Percentage of nondirected donors (NDDs) by ABO blood type by year of donation, 1988-2015.

5772 in 2011, and has yet to exceed 2010 levels. Thus, the decline in NDDs seems to be related to a more widespread phenomenon that has affected the entire country, rather than an isolated drop in NDDs.

In our analysis, the NDD population skews male, with men making up $59.14 \%$ of the total NDD population to date. This differs from prior reports, in which the majority of NDDs were female. It is unclear why this might be the case, though these results are in line with the overall LD population, which has been majority male every year since 1988 .

NDDs are overwhelmingly white and US citizens. Of the other ethnicities tracked by UNOS, their numbers have tended to jump around from year to year; this is likely due to the fact that there are far fewer NDDs performed each year, and more of a chance of variability from one year to the next. That NDDs tend to be US citizens is no surprise; of all the citizenship groups listed, citizens tend to have better access to care, and, as permanent residents of the US, can choose to donate when the time is right for them. Non-citizens, on the other hand, may have a limited stay in the US due to visa requirements.

Regionally, UNOS Region 5 is the most prolific region for NDDs, and for overall LDs. This region contains California, the most populated state in the country, and in total is the home for over 50 million people, roughly one-sixth of the population of the US. It is no surprise that the most non-directed donations are performed in this region. UNOS Region 9, on the other hand, is far more prolific in its NDD involvement than its overall LD number would suggest; despite performing the sixthmost LD surgeries, just $7.81 \%$ of them historically, they have performed $16.07 \%$ of the NDD surgeries to date, the second-most in the nation. Region 9 does contain New York City, the most populated city in the country - home to 20 million people. That Region 9 has $40 \%$ of the population of Region 5 and performs roughly the same number of nondirected donations each year suggests that Region 9 is a very active area for NDDs. Whether this is due to local laws or outreach programs is, in our view, an important area of future research.

Since the first recent reports of NDDs appeared in the literature in 2000, non-directed donations have become an increasing part of the living donor pool nationwide. These non-directed donations are critically important, not only because they expand the donor pool, but also because they often act as a starting point for increasingly used kidney donation chains. Our analysis has shown that the annual percentage of NDDs as a total of overall LDs is increasing, becoming more important each year as a source of kidneys; NDDs tending to be male, white, and US citizens; and that some UNOS regions are more engaging in working with NDDs (Regions 5, 9, and 7) than are others. Understanding the characteristics of NDDs is an exciting area of research, and one that deserves continued study and updating over the coming years.

\section{References}

1. Jacobs CL, Roman D, Garvey C, Kahn J, Matas AJ (2004) Twenty-two nondirected kidney donors: an update on a single center's experience. Am J Transplant 4: 1110-1116.

2. Matas AJ, Garvey CA, Jacobs CL, Kahn JP (2000) Nondirected donation of kidneys from living donors. N Engl J Med 343: 433-436.

3. Adams PL, Cohen DJ, Danovitch GM, Edington RM, Gaston RS, et al (2002) The nondirected live-kidney donor: ethical considerations and practice guidelines: A National Conference Report. Transplantation 74: 582-589.

4. Maple H, Chilcot J, Burnapp L, Gibbs P, Santhouse A, et al. (2014) Motivations, outcomes, and characteristics of unspecified (nondirected altruistic) kidney donors in the United Kingdom. Transplantation 98: 1182-1189.

5. Lennerling A, Fehrman-Ekholm I, Norden G (2008) Nondirected living kidney donation: experiences in a Swedish Transplant Centre. Clin Transplant 22 304-308.

6. Mark PJ, Baker K, Aguayo C, Sorensen JB (2006) Experience with an organ procurement organization-based non-directed living kidney donation programme. Clin Transplant 20: 427-437.

7. Morrissey PE, Dube C, Gohh R, Yango A, Gautam A, et al. (2005) Good samaritan kidney donation. Transplantation 80: 1369-1373.

8. Rodrigue JR, Schutzer ME, Paek M, Morissey P (2011) Altruistic kidney donation to a stranger: psychosocial and functional outcomes at two US transplant centers. Transplantation 91: 772-778.

9. Massey EK, Kranenburg LW, Zuidema WC, Hak G, Erdman RA (2010) Encouraging psychological outcomes after altruistic donation to a stranger. Am J Transplant 10: 1445-1452. 
Citation: Faber DA, Joshi S, Ciancio G (2016) Demographic Characteristics of Non-directed Altruistic Kidney Donors in the United States. J Kidney 2: 121. doi: $10.4172 / 2472-1220.1000121$

Page 5 of 5

10. Jacobs CL, Matas AJ (2003) Nondirected kidney donation practice in the United States. Am J Transplant 3: 178.

11. Griffin JL, Moron J (2011) Altruistic kidney donation: donor characteristics and outcomes from 11 years' experience. Br J Surg 98: 147
12. Brethel-Haurwitz KM, Marsh AA (2014) Geographical differences in subjective well-being predict extraordinary altruism. Psychol Sci 25: 762-771.

13. Organ Procurement and Transplantation Network (2015) Living Donor Transplants in the US by Donor Relation. 